\title{
Hsa-miR-3651 could serve as a novel predictor for in-breast recurrence via FRMD3
}

\author{
Barbara Zellinger ${ }^{2,3}$. Ulrich Bodenhofer ${ }^{4,5} \cdot$ Immanuela A. Engländer $^{1,2} \cdot$ Cornelia Kronberger $^{3} \cdot$ Brane Grambozov $^{1}$. \\ Elvis Ruznic ${ }^{1} \cdot$ Markus Stana $^{1} \cdot$ Josef Karner ${ }^{1} \cdot$ Gerd Fastner $^{1} \cdot$ Karl Sotlar $^{3} \cdot$ Felix Sedlmayer $^{1,2} \cdot$ Franz Zehentmayr $^{1,2}$ (D)
}

Received: 6 May 2021 / Accepted: 25 October 2021 / Published online: 5 December 2021

(c) The Author(s) 2021

\begin{abstract}
Background MicroRNAs are small non-coding RNAs with pivotal regulatory functions in multiple cellular processes. Their significance as molecular predictors for breast cancer was demonstrated in the past 15 years. The aim of this study was to elucidate the role of hsa-miR-3651 for predicting of local control (LC) in early breast cancer.

Results By means of high-throughput technology, hsa-miR-3651 was found to be differentially expressed between patients who experienced local relapse compared to those without $(N=23 ; p=0.0035)$. This result could be validated in an independent cohort of 87 patients using RT-qPCR $(p<0.0005)$. In a second analysis step with a chip-based microarray containing 70,523 probes of potential target molecules, FERM domain protein 3 (FRMD3) was found to be the most down-regulated protein $(N=21 ; p=0.0016)$. Computational analysis employing different prediction algorithms revealed FRMD3 as a likely downstream target of hsa-miR-3651 with an 8mer binding site between the two molecules. This could be validated in an independent patient set $(N=20, p=0.134)$.

Conclusion The current study revealed that hsa-miR-3651 is a predictor of LC in early breast cancer via its putative target protein FRMD3. Since microRNAs interfere in multiple pathways, the results of this hypothesis generating study may contribute to the development of tailored therapies for breast cancer in the future.
\end{abstract}

Keywords Hsa-miR-3651 $\cdot$ FRMD3 $\cdot$ Early breast cancer $\cdot$ Local control $\cdot$ Prediction

\section{Abbreviations}

AUC

Area under the curve

BCT

DdPCR

Breast conserving therapy

DFS

Droplet digital PCR

Disease free survival

Franz Zehentmayr

f.zehentmayr@salk.at

1 Department of Radiation Oncology, Paracelsus Medical University, SALK, Müllner Hauptstrasse 48, 5020 Salzburg, Austria

2 radART-Institute for Research and Development on Advanced Radiation Technologies, Paracelsus Medical University, Salzburg, Austria

3 Department of Pathology, Paracelsus Medical University, SALK, Salzburg, Austria

4 School of Informatics, Communications and Media, University of Applied Sciences Upper Austria, Hagenberg, Austria

5 Institute for Machine Learning, Johannes Kepler University, Linz, Austria

$\begin{array}{ll}\text { EBCTG } & \text { Early Breast Cancer Trialist Group } \\ \text { FERM } & \begin{array}{l}\text { Four-point-one, ezrin, radixin, moesin } \\ \text { domain }\end{array} \\ \text { FFPE } & \text { Formalin fixed paraffin embedded } \\ \text { FRMD3 } & \text { FERM domain containing protein 3 } \\ \text { LC } & \text { Local control } \\ \text { LIMMA } & \text { Linear models for micro-array analyses } \\ \text { miRNA, miR } & \text { MicroRNA } \\ \text { ncRNA } & \text { Non-coding RNA } \\ \text { NSCLC } & \text { Non-small cell lung cancer } \\ \text { OS } & \text { Overall survival } \\ \text { OSCC } & \text { Oral squamous cell carcinoma } \\ \text { PSVM } & \text { Potential support vector machine } \\ \text { RISC } & \text { RNA-induced silencing complex } \\ \text { RMA } & \text { Robust machine learning algorithms } \\ \text { ROC } & \text { Receiver operating curve } \\ \text { RT-Qpcr } & \text { Real-time quantitative polymerase chain } \\ & \text { reaction } \\ \text { 3’UTR } & \text { Untranslated region }\end{array}$




\section{Introduction}

The breast cancer mortality rate in Europe is predicted to be 13.4 per 1,00,000 for 2020 [1]. Loco-regional control is a cornerstone for long-term cure. An analysis by the Early Breast Cancer Trialist Group (EBCTG) revealed a 4:1 relation between local relapse and breast cancer specific death [2]. Therapeutic advances in all disciplines related to breast conserving therapy (BCT) have led to low local relapse rates, with age being the most important predictor. The estimates for age adjusted annual in-breast recurrence are $0.4-0.7 \%$ for patients $>50$ years, $0.72-1.2 \%$ in the age group $41-50$ years, and $0.72-2 \%$ for patients younger than 40 years, respectively [3]. As the prevention of local relapse is fundamental for long-term cancer free survival especially in younger patients [2], pre-therapeutic molecular tumor profiling is increasingly important.

MicroRNAs are small non-coding RNAs (ncRNA) of 20-25 nucleotides, which interfere in multiple (patho)physiological processes via transcriptional regulation. During the past 2 decades, they have emerged as a new class of predictive and prognostic markers in various types of cancer. As for breast cancer, Iorio suggested a miR-signature, describing a panel of de-regulated miRs correlated with known clinical and biological features such as hormonal receptor status, tumor size, lymph node status, vascular invasion, proliferation index and p53 [4]. Integrating of molecular markers in the clinical subtyping of breast cancer [5] opens up the way for ncRNA as a prediction tool in the future. The significance of microRNAs for local control (LC) could be demonstrated in three previous publications [6-8]. While hsa-miR-3651 has been described in other cancer types such as head and neck [9, 10], ovarian [11], colorectal [12], liver [13] and lung [14], the current study is the first to demonstrate its relevance in breast cancer. Thus far, no data are extant on its potential target proteins, let alone a potential pathway which it could interfere in. Computational analyses suggested FERM domain containing protein 3 (FRMD3), a member of the protein 4.1 superfamily, as a putative downstream target, which is involved in cytoskeletal protein binding and seems to play a role in cell motility and invasiveness [15-17].

The aim of the current study was to identify microRNAs that could predict in-breast recurrence in locoregionally highly invasive early stage breast cancers. This hypothesis-generating study is meant to enlarge the spectrum of tailored therapies for this disease in the future.

\section{Methods}

\section{Experimental design and clinical endpoint}

The first step of the current study was conducted in a pilot phase by means of high-throughput technology to screen for de-regulated microRNAs with a subsequent validation phase using real-time polymerase chain reaction (RTqPCR, supplementary file 1). A crucial point in studies like this is the heterogeneous microRNA expression in the various tissue compartments of a sample representing the molecular difference between stroma and cancer [18]. While some analyses in FFPE material were performed after microdissection [19] in order to enhance the tumor signal, we-similar to Lyng [20]—selected patient samples with a minimum tumor content of 50\%. Additionally, this investigation emphasizes the role of single miRNAs. In fact, most analyses also include clustered microRNAs, which are potentially overrepresented in the miRnome because of their enhanced transcriptional efficacy based on genomic proximity [21]. In a second step, computational research was combined with a microarray to screen for potential target proteins, which was followed by a validation phase employing droplet digital polymerase chain reaction (ddPCR). While in most studies survival is the clinical endpoint $[19,20]$, in the current study it is local relapse defined as the re-appearance of cancer in the same breast [22].

\section{Patients}

The patients in this investigation constitute a sub-population characterized by enhanced loco-regional invasiveness (i.e., higher T-, $\mathrm{N}$-stage and increased probability of in-situ component) compared to the main cohort [7,8]. One-hundred and ten patients were included. Thirty-seven patients with local in-breast recurrences were matched to 73 controls without relapse, according to the following criteria: year of diagnosis, type of surgery (mastectomy or lumpectomy), type of radiotherapy (whole breast irradiation with percutaneous or intraoperative boost), age, tumor size, lymph node involvement, grading, histology, hormonal receptor status, her 2 status, menopausal status, Ki67 proliferation index (Tables 1, 2, 3, 4). The miRNA pilot phase included 13 patients and 10 controls, while the remaining 87 patients ( 24 relapses/63 controls) constituted the validation cohort. The analysis for potential target proteins was planned to be carried out in the very same patient data set and biological material. However, due to RNA degradation in the pathologic specimen that precluded proper signal detection in some cases and 
Table 1 Clinical and therapeutic parameters of the patients analyzed for hsa-miR-3651

\begin{tabular}{|c|c|c|c|c|c|c|}
\hline \multirow[t]{2}{*}{ Parameters } & \multicolumn{3}{|l|}{ Pilot phase $N=23$} & \multicolumn{3}{|c|}{ Validation phase $N=87$} \\
\hline & Relapse $N=13(\%)$ & Control $N=10(\%)$ & $p$ value & Relapse $N=24(\%)$ & Control $N=63(\%)$ & $p$ value \\
\hline \multicolumn{7}{|l|}{ Age at diagnosis (years) } \\
\hline Median & 57 & 54 & \multirow[t]{2}{*}{0.784} & 50 & 52 & \multirow[t]{2}{*}{0.658} \\
\hline Range & $36-71$ & $35-74$ & & $33-79$ & $37-78$ & \\
\hline \multicolumn{7}{|l|}{ Menopause $(N)$} \\
\hline No & $3(23 \%)$ & $2(20 \%)$ & \multirow[t]{3}{*}{0.842} & $9(38 \%)$ & $29(46 \%)$ & \multirow[t]{3}{*}{0.126} \\
\hline Yes & $7(54 \%)$ & $5(50 \%)$ & & $14(58 \%)$ & $26(41 \%)$ & \\
\hline Unclear & $3(23 \%)$ & $3(30 \%)$ & & $1(4 \%)$ & $8(13 \%)$ & \\
\hline \multicolumn{7}{|l|}{$\mathrm{T}(N)$} \\
\hline $\mathrm{T} 1$ & $7(54 \%)$ & $4(40 \%)$ & \multirow[t]{2}{*}{0.738} & $20(83 \%)$ & $54(86 \%)$ & \multirow[t]{2}{*}{0.904} \\
\hline $\mathrm{T} 2$ & $6(46 \%)$ & $6(60 \%)$ & & $4(17 \%)$ & $9(14 \%)$ & \\
\hline \multicolumn{7}{|l|}{$\mathrm{N}(N)$} \\
\hline N0 & $11(85 \%)$ & $7(70 \%)$ & \multirow[t]{3}{*}{0.832} & $18(75 \%)$ & $49(78 \%)$ & \multirow[t]{3}{*}{0.989} \\
\hline N1 & $1(8 \%)$ & $2(20 \%)$ & & $6(25 \%)$ & $17(22 \%)$ & \\
\hline $\mathrm{N} 2$ & $1(8 \%)$ & $1(10 \%)$ & & $0(0 \%)$ & $0(0 \%)$ & \\
\hline \multicolumn{7}{|l|}{$\mathrm{M}(N)$} \\
\hline M0 & $13(100 \%)$ & $10(100 \%)$ & 1 & $24(100 \%)$ & $66(100 \%)$ & 1 \\
\hline \multicolumn{7}{|l|}{ Grading $(N)$} \\
\hline G1 & $0(0 \%)$ & $0(0 \%)$ & \multirow[t]{3}{*}{0.784} & $3(13 \%)$ & $5(8 \%)$ & \multirow[t]{3}{*}{0.434} \\
\hline $\mathrm{G} 2$ & $6(46 \%)$ & $5(50 \%)$ & & $13(54 \%)$ & $44(70 \%)$ & \\
\hline G3 & $7(54 \%)$ & $5(50 \%)$ & & $8(33 \%)$ & $14(22 \%)$ & \\
\hline \multicolumn{7}{|l|}{ Histology $(N)$} \\
\hline IDC & $11(85 \%)$ & $10(100 \%)$ & \multirow[t]{3}{*}{0.784} & $17(71 \%)$ & $51(81 \%)$ & \multirow[t]{3}{*}{0.246} \\
\hline ILC & $2(15 \%)$ & $0(0 \%)$ & & $4(17 \%)$ & $6(8.5 \%)$ & \\
\hline Other & $0(0 \%)$ & $0(0 \%)$ & & $3(13 \%)$ & $6(8.5 \%)$ & \\
\hline In situ component $(N)$ & & & & & & \\
\hline Yes & $12(92 \%)$ & $3(30 \%)$ & 0.376 & $14(58 \%)$ & $40(63 \%)$ & 0.569 \\
\hline No & $1(8 \%)$ & $7(70 \%)$ & & $10(42 \%)$ & $23(37 \%)$ & \\
\hline Receptors $(N)$ & & & & & & \\
\hline ER positive & $6(46 \%)$ & $6(60 \%)$ & 0.605 & $18(75 \%)$ & $51(81 \%)$ & 0.459 \\
\hline ER negative & $7(54 \%)$ & $4(40 \%)$ & & $6(25 \%)$ & $12(19 \%)$ & \\
\hline PR positive & $7(54 \%)$ & $4(40 \%)$ & 0.446 & $17(71 \%)$ & $46(73 \%)$ & 0.723 \\
\hline PR negative & $6(46 \%)$ & $6(60 \%)$ & & $7(29 \%)$ & $17(27 \%)$ & \\
\hline her2neu $(N)$ & & & & & & \\
\hline Positive & $8(62 \%)$ & $3(30 \%)$ & 0.208 & $9(38 \%)$ & $18(29 \%)$ & 0.725 \\
\hline Negative & $5(38 \%)$ & $7(70 \%)$ & & $14(58 \%)$ & $33(52 \%)$ & \\
\hline Not assessable & $0(0 \%)$ & $0(0 \%)$ & & $1(4 \%)$ & $12(18 \%)$ & \\
\hline Proliferation index $(N)$ & & & & & & \\
\hline ki67 <20\% & $8(62 \%)$ & $3(30 \%)$ & 0.208 & $14(58 \%)$ & $46(73 \%)$ & 0.179 \\
\hline ki67 $>20 \%$ & $5(38 \%)$ & $7(70 \%)$ & & $10(42 \%)$ & $17(27 \%)$ & \\
\hline Not assessable & $0(0 \%)$ & $0(0 \%)$ & & $0(0 \%)$ & $0(0 \%)$ & \\
\hline Boost & & & & & & \\
\hline Intraoperative $(N)$ & $7(54 \%)$ & $5(50 \%)$ & 0.879 & $10(42 \%)$ & $24(38 \%)$ & 0.996 \\
\hline Percutaneous $(N)$ & $6(46 \%)$ & $5(50 \%)$ & & $14(58 \%)$ & $39(62 \%)$ & \\
\hline None & $0(0 \%)$ & $0(0 \%)$ & & $0(0 \%)$ & $0(0 \%)$ & \\
\hline Intraoperative dose (Gy) & 10 & 10 & & 10 & 10 & \\
\hline Percutaneous dose (Gy) & 12 & 12 & & 12 & 12 & \\
\hline
\end{tabular}


Table 1 (continued)

\begin{tabular}{|c|c|c|c|c|c|c|}
\hline \multirow[t]{2}{*}{ Parameters } & \multicolumn{3}{|l|}{ Pilot phase $N=23$} & \multicolumn{3}{|c|}{ Validation phase $N=87$} \\
\hline & Relapse $N=13(\%)$ & Control $N=10(\%)$ & $p$ value & Relapse $N=24(\%)$ & Control $N=63(\%)$ & $p$ value \\
\hline \multicolumn{7}{|c|}{ WBRT dose (Gy) } \\
\hline Median & 54 & 54 & 0.648 & 54 & 54 & 0.571 \\
\hline Range & $52.2-55.6$ & $51-56$ & & $51-59$ & $52.2-57$ & \\
\hline \multicolumn{7}{|l|}{ Surgery $(N)$} \\
\hline BCT & $13(100 \%)$ & $10(100 \%)$ & 0.693 & $24(100 \%)$ & $63(100 \%)$ & 1 \\
\hline Mastectomy & $0(0 \%)$ & $0(0 \%)$ & & $0(0 \%)$ & $00 \%)$ & \\
\hline \multicolumn{7}{|c|}{$\operatorname{Re}$-excision $(N)$} \\
\hline Yes & $5(38 \%)$ & $1(10 \%)$ & 0.483 & $10(42 \%)$ & $27(43 \%)$ & 0.8 \\
\hline No & $8(62 \%)$ & $9(90 \%)$ & & $14(58 \%)$ & $36(57 \%)$ & \\
\hline \multicolumn{7}{|c|}{ Year of surgery $(N)$} \\
\hline Before 1998 & $3(23 \%)$ & $3(30 \%)$ & 0.784 & $12(50 \%)$ & $31(49 \%)$ & 0.76 \\
\hline Since 1998 & $10(77 \%)$ & $7(70 \%)$ & & $12(50 \%)$ & $32(51 \%)$ & \\
\hline \multicolumn{7}{|c|}{ Chemotherapy $(N)$} \\
\hline Yes & $6(46 \%)$ & $4(40 \%)$ & 0.41 & $9(38 \%)$ & $16(26 \%)$ & 0.168 \\
\hline No & $7(54 \%)$ & $6(60 \%)$ & & $15(63 \%)$ & $47(74 \%)$ & \\
\hline \multicolumn{7}{|c|}{ Anti-hormonal treatment $(N)$} \\
\hline Yes & $8(62 \%)$ & $4(40 \%)$ & 0.522 & $13(54 \%)$ & $42(67 \%)$ & 0.203 \\
\hline No & $5(38 \%)$ & $6(60 \%)$ & & $10(42 \%)$ & $19(30 \%)$ & \\
\hline Unclear & $0(0 \%)$ & $0(0 \%)$ & & $1(4 \%)$ & $2(3 \%)$ & \\
\hline \multicolumn{7}{|c|}{ Tumor burden $(\%)$} \\
\hline Median & 70 & 70 & 0.101 & 70 & 70 & 0.401 \\
\hline Range & $50-90$ & $50-90$ & & $50-90$ & $50-90$ & \\
\hline
\end{tabular}

Table 2 Clinical outcome of the patients analyzed for hsamiR-3651

\begin{tabular}{|c|c|c|c|c|}
\hline \multicolumn{5}{|l|}{ Clinical outcome $N=110$} \\
\hline \multirow[t]{2}{*}{ Parameter } & \multicolumn{2}{|c|}{ Pilot phase $N=23$} & \multicolumn{2}{|c|}{ Validation phase $N=87$} \\
\hline & Relapse $N=13$ & Control $N=10$ & Relapse $N=24$ & Control $N=63$ \\
\hline \multicolumn{5}{|l|}{ Follow up (months) } \\
\hline Median & 139 & 133 & 125 & 142 \\
\hline Range & $26-190$ & $98-187$ & 44-196 & $17-207$ \\
\hline Cancer related deaths $(N)$ & $3(23 \%)$ & $0(0 \%)$ & $6(25 \%)$ & $0(0 \%)$ \\
\hline Local relapse & $13(100 \%)$ & $0(0 \%)$ & $24(100 \%)$ & $0(0 \%)$ \\
\hline Distant metastasis & $2(15 \%)$ & $0(0 \%)$ & $7(29 \%)$ & $0(0 \%)$ \\
\hline
\end{tabular}

forensic restrictions in others the cohort had to be reduced to 21 (13 relapses/8 controls) in the pilot phase and 20 (9 relapses/11 controls) in the validation phase.

The study was approved by the ethics committee of Salzburg (415-EP/73/85-2012 and 415-EP/73/582-2015). Informed consent was obtained from all individual participants included in the study.

\section{Samples}

Tumor tissue from patients with early stage breast cancer retrieved during breast conserving surgery was formalin fixed paraffin embedded (FFPE) and stored in the tissue bank of the Department of Pathology. For the current analysis only samples with a minimum tumor content 
Table 3 Clinical and therapeutic parameters of the patients analyzed for FRMD3

Patient and treatment characteristics $N=41$

\begin{tabular}{|c|c|c|c|c|c|c|}
\hline \multirow[t]{2}{*}{ Parameters } & \multicolumn{3}{|l|}{ Pilot phase $N=21$} & \multicolumn{3}{|c|}{ Validation phase $N=20$} \\
\hline & Relapse $N=13(\%)$ & Control $N=8(\%)$ & $p$ value & Relapse $N=9(\%)$ & Control $N=11(\%)$ & $p$ value \\
\hline \multicolumn{7}{|c|}{ Patient characteristics } \\
\hline \multicolumn{7}{|c|}{ Age at diagnosis (years) } \\
\hline Median & 57 & 62.5 & 0.336 & 57 & 56 & 0.295 \\
\hline Range & $36-71$ & $41-74$ & & $40-79$ & $44-78$ & \\
\hline \multicolumn{7}{|l|}{ Menopause $(N)$} \\
\hline No & $3(23 \%)$ & $1(13 \%)$ & 0.633 & $2(22 \%)$ & $4(36 \%)$ & 0.603 \\
\hline Yes & $7(54 \%)$ & $5(63 \%)$ & & $7(78 \%)$ & $7(64 \%)$ & \\
\hline Unclear & $3(23 \%)$ & $2(25 \%)$ & & $0(0 \%)$ & $0(0 \%)$ & \\
\hline \multicolumn{7}{|l|}{$\mathrm{T}(N)$} \\
\hline $\mathrm{T} 1$ & $7(54 \%)$ & $2(25 \%)$ & 1 & $8(89 \%)$ & $9(82 \%)$ & 0.824 \\
\hline $\mathrm{T} 2$ & $6(46 \%)$ & $6(75 \%)$ & & $1(11 \%)$ & $2(18 \%)$ & \\
\hline \multicolumn{7}{|l|}{$\mathrm{N}(N)$} \\
\hline NO & $11(85 \%)$ & $6(75 \%)$ & 0.595 & $7(78 \%)$ & $5(45 \%)$ & 0.412 \\
\hline N1 & $1(8 \%)$ & $1(13 \%)$ & & $2(22 \%)$ & $6(55 \%)$ & \\
\hline N2 & $1(8 \%)$ & $1(13 \%)$ & & $0(0 \%)$ & $0(0 \%)$ & \\
\hline \multicolumn{7}{|l|}{$\mathrm{M}(N)$} \\
\hline M0 & $13(100 \%)$ & $8(100 \%)$ & 1 & $9(100 \%)$ & $11(100 \%)$ & 1 \\
\hline \multicolumn{7}{|l|}{ Grading $(N)$} \\
\hline G1 & $0(0 \%)$ & $0(0 \%)$ & 0.804 & $2(22 \%)$ & $2(18 \%)$ & 0.941 \\
\hline $\mathrm{G} 2$ & $6(46 \%)$ & $4(50 \%)$ & & $4(44 \%)$ & $6(55 \%)$ & \\
\hline G3 & $7(54 \%)$ & $4(50 \%)$ & & $3(33 \%)$ & $3(27 \%)$ & \\
\hline \multicolumn{7}{|l|}{ Histology $(N)$} \\
\hline IDC & $11(85 \%)$ & $8(100 \%)$ & 0.804 & $6(67 \%)$ & $10(91 \%)$ & 0.37 \\
\hline ILC & $2(15 \%)$ & $0(0 \%)$ & & $1(11 \%)$ & $0(0 \%)$ & \\
\hline Other & $0(0 \%)$ & $0(0 \%)$ & & $2(22 \%)$ & $1(9 \%)$ & \\
\hline \multicolumn{7}{|c|}{ In situ component $(N)$} \\
\hline Yes & $12(92 \%)$ & $5(63 \%)$ & 0.268 & $3(33 \%)$ & $8(73 \%)$ & 0.152 \\
\hline No & $1(8 \%)$ & $3(38 \%)$ & & $6(67 \%)$ & $3(27 \%)$ & \\
\hline \multicolumn{7}{|l|}{ Receptors $(N)$} \\
\hline ER positive & $6(46 \%)$ & $4(50 \%)$ & 0.547 & $6(67 \%)$ & $9(82 \%)$ & 0.603 \\
\hline ER negative & $7(54 \%)$ & $4(50 \%)$ & & $3(33 \%)$ & $2(18 \%)$ & \\
\hline PR positive & $7(54 \%)$ & $3(38 \%)$ & 0.5 & $6(67 \%)$ & $7(64 \%)$ & 0.941 \\
\hline PR negative & $6(46 \%)$ & $5(63 \%)$ & & $3(33 \%)$ & $4(36 \%)$ & \\
\hline \multicolumn{7}{|l|}{ her2neu $(N)$} \\
\hline Positive & $8(62 \%)$ & $1(13 \%)$ & 0.064 & $3(33 \%)$ & $4(36 \%)$ & 0.73 \\
\hline Negative & $5(38 \%)$ & $7(88 \%)$ & & $6(67 \%)$ & $5(45 \%)$ & \\
\hline Not assessable & $0(0 \%)$ & $0(0 \%)$ & & $0(100 \%)$ & $2(18 \%)$ & \\
\hline \multicolumn{7}{|c|}{ Proliferation index $(N)$} \\
\hline ki67 $<20 \%$ & $8(62 \%)$ & $3(38 \%)$ & 0.374 & $6(67 \%)$ & $6(55 \%)$ & 0.656 \\
\hline ki67 > 20\% & $5(38 \%)$ & $5(63 \%)$ & & $3(33 \%)$ & $5(45 \%)$ & \\
\hline Not assessable & $0(0 \%)$ & $0(0 \%)$ & & $0(0 \%)$ & $0(0 \%)$ & \\
\hline
\end{tabular}


Table 3 (continued)

Patient and treatment characteristics $N=41$

\begin{tabular}{|c|c|c|c|c|c|c|}
\hline \multirow[t]{2}{*}{ Parameters } & \multicolumn{3}{|l|}{ Pilot phase $N=21$} & \multicolumn{3}{|c|}{ Validation phase $N=20$} \\
\hline & Relapse $N=13(\%)$ & Control $N=8(\%)$ & $p$ value & Relapse $N=9(\%)$ & Control $N=11(\%)$ & $p$ value \\
\hline \multicolumn{7}{|l|}{ Treatment } \\
\hline \multicolumn{7}{|l|}{ Boost } \\
\hline Intraoperative $(N)$ & $7(54 \%)$ & $4(50 \%)$ & 0.916 & $6(67 \%)$ & $7(64 \%)$ & 0.941 \\
\hline Percutaneous $(N)$ & $6(46 \%)$ & $4(50 \%)$ & & $3(33 \%)$ & $4(36 \%)$ & \\
\hline None & $0(0 \%)$ & $0(0 \%)$ & & $0(0 \%)$ & $0(0 \%)$ & \\
\hline Intraoperative dose (Gy) & 10 & 10 & & 10 & 10 & \\
\hline Percutaneous dose (Gy) & 12 & 12 & & 12 & 12 & \\
\hline \multicolumn{7}{|l|}{ WBRT dose (Gy) } \\
\hline Median & 54 & 54 & 1 & 54 & 10 & 1 \\
\hline Range & $52.2-55.6$ & $54-56$ & & $51-59$ & $10-12$ & \\
\hline \multicolumn{7}{|l|}{ Surgery $(N)$} \\
\hline BCT & $13(100 \%)$ & $8(100 \%)$ & 1 & $9(100 \%)$ & $11(100 \%)$ & 1 \\
\hline Mastectomy & $0(0 \%)$ & $0(0 \%)$ & & $0(0 \%)$ & $0(0 \%)$ & \\
\hline \multicolumn{7}{|l|}{ Re-excision $(N)$} \\
\hline Yes & $5(38 \%)$ & $0(0 \%)$ & 0.645 & $2(22 \%)$ & $8(73 \%)$ & 0.056 \\
\hline No & $8(62 \%)$ & $8(100 \%)$ & & $7(78 \%)$ & $3(27 \%)$ & \\
\hline \multicolumn{7}{|l|}{ Year of surgery $(N)$} \\
\hline Before 1998 & $3(23 \%)$ & $2(25 \%)$ & 1 & $3(33 \%)$ & $4(36 \%)$ & 0.941 \\
\hline Since 1998 & $10(77 \%)$ & $6(75 \%)$ & & $6(67 \%)$ & $7(64 \%)$ & \\
\hline \multicolumn{7}{|l|}{ Chemotherapy $(N)$} \\
\hline Yes & $6(46 \%)$ & $3(38 \%)$ & 0.185 & $2(22 \%)$ & $2(18 \%)$ & 0.882 \\
\hline No & $7(54 \%)$ & $5(63 \%)$ & & $7(78 \%)$ & $9(82 \%)$ & \\
\hline \multicolumn{7}{|l|}{ Anti-hormonal treatment $(N)$} \\
\hline Yes & $8(62 \%)$ & $3(38 \%)$ & 0.75 & $6(67 \%)$ & $8(73 \%)$ & 0.824 \\
\hline No & $5(38 \%)$ & $5(63 \%)$ & & $2(22 \%)$ & $3(27 \%)$ & \\
\hline Unclear & $0(0 \%)$ & $0(0 \%)$ & & $1(11 \%)$ & $0(0 \%)$ & \\
\hline \multicolumn{7}{|l|}{ Tumor burden $(\%)$} \\
\hline Median & 70 & 70 & 0.185 & 70 & 50 & 0.603 \\
\hline Range & $50-90$ & $50-90$ & & $50-90$ & $50-90$ & \\
\hline
\end{tabular}

Table 4 Clinical outcome of the patients analyzed for FRMD3

\begin{tabular}{|c|c|c|c|c|}
\hline \multicolumn{5}{|l|}{ Clinical outcome $N=41$} \\
\hline \multirow[t]{2}{*}{ Parameter } & \multicolumn{2}{|c|}{ Pilot phase $N=21$} & \multicolumn{2}{|c|}{ Validation phase $N=20$} \\
\hline & Relapse $N=13$ & Control $N=8$ & Relapse $N=9$ & Control $N=11$ \\
\hline \multicolumn{5}{|l|}{ Follow up (months) } \\
\hline Median & 139 & 133 & 110 & 124 \\
\hline Range & 26-190 & 98-187 & 44-192 & $72-195$ \\
\hline Cancer-related deaths $(N)$ & $3(23 \%)$ & $0(0 \%)$ & $2(22 \%)$ & $0(0 \%)$ \\
\hline Local relapse & $13(100 \%)$ & $0(0 \%)$ & $9(100 \%)$ & $0(0 \%)$ \\
\hline Distant metastasis & $2(15 \%)$ & $0(0 \%)$ & $2(22 \%)$ & $0(0 \%)$ \\
\hline
\end{tabular}

of $50 \%$ were eligible. Seven consecutive sections per patient were prepared. Isolation of total miR and chipbased microarrays (Agilent's Sure PrintG3 Human miRNA microarrays ${ }^{\mathrm{TM}}$ ) were performed according to standard procedures by our external partner, the Comprehensive Biomarker Center ${ }^{\mathrm{TM}}(\mathrm{CBC})$, Heidelberg. 


\section{MiRNA_pilot phase: microarray}

The tumors of patients who experienced local relapse were compared to controls in order to screen for the most deregulated microRNAs. The relative expression levels were calculated as fold change (relapse/control) with the $\Delta \Delta \mathrm{C}_{\mathrm{t}}$ comparative threshold method [23]. This part of the study was carried out by the external partner.

\section{MiRNA—validation phase: RT-qPCR procedure and data analysis}

The most significantly de-regulated microRNA was tested in a separate cohort of 87 patients (24 relapses, 63 controls) by means of RT-qPCR. Briefly, small RNA molecules were extracted with miRNeasy FFPE kit (Qiagen ${ }^{\mathrm{TM}}$ ) and quantified fluorometrically with Qubit ${ }^{\mathrm{TM}}$ RNA Assay Kit (Invitrogen ${ }^{\mathrm{TM}}$ ). cDNA synthesis was performed with miScript II Kit (Qiagen ${ }^{\mathrm{TM}}$ ), and RT-qPCR analysis was done with miScript SYBR Green PCR Kit (Qiagen ${ }^{\mathrm{TM}}$ ) on Rotor-Gene (Qiagen ${ }^{\mathrm{TM}}$ ). A detailed description of each RT-qPCR step with respect to RNA extraction, reverse transcription, real time PCR and qPCR validation was previously published [7]. All samples were analyzed in duplicate reactions.

\section{Target proteins_pilot phase: microarray}

A microarray for potential target proteins was carried out in the same FFPE samples that were used for the microRNA screen ("Patients" Section). Two patients had to be excluded for lack of biopsy material, which reduced the number of eligible specimen to 21 (13 relapses/8 controls). An in-silico search in six different databases (TargetScan, miRDB, PITA, DIANA, DIANA Cancer, accessed in May 2015; miRCarta accessed February 2021) was followed by a microarray (Affymetrix GeneChip Human Transcriptome Array 2.0 ${ }^{\circledR}$ ) containing 70,523 probes. From each sample, 5 nanogram total RNA was processed with the Affymetrix GeneChip WT Pico Reagent $\mathrm{Kit}^{\circledR}$, which resulted in $5.5 \mu \mathrm{g}$ ss-cDNA. Fragmenting, labelling and hybridization to the GeneChip ${ }^{\circledR}$ were performed according to the manufacturer's instructions. The microarray was processed with the Gene Chip Hybridization Oven 645, Gene Chip Scanner and Gene Chip Fluidics Station 450 Dx (Affymetrix ${ }^{\circledR}$, Thermo Fisher Scientific ${ }^{\circledR}$ ). For image quality control the normalized unscaled standard error (NUSE) was used, which measures the accuracy of the expression data in relation with the other arrays in the batch [24].

\section{Target proteins validation phase}

Tissue preparation was done according to the protocols provided by Promega ${ }^{\circledR}$, while ddPCR and data analysis followed the BioRad ${ }^{\circledR}$ manuals. A detailed description of the various steps of the target protein validation phase was previously published [8].

\section{Statistics}

The microarray output data were analyzed with the robust machine learning algorithm (RMA) [25] from the oligopackage [26]. Differentially expressed microRNAs and target genes were selected as candidates for further validation according to their fold change and statistical significance estimated with the moderated t-test (linear models for micro-array analysis, LIMMA) [27]. Multiple testing was accounted for by the Benjamin-Hochberg correction method [28]. The Mann-Whitney test was used to compare $\Delta \mathrm{Ct}$-values, patient-, tumor- and treatment related characteristics between relapse and control groups. To generate a combined marker, the values for microRNA and target protein were ranked. Subsequently, these indices were subtracted from each other. Since an inverse relation between the microRNA and its target molecule could be assumed, the one-sided Pearson correlation test was used. Because of a reduced number of patients in the target validation phase the significance threshold was set at 0.2 for first order errors $(\alpha)$ in order to retain as much potentially predictive information as possible [29]. LC was estimated by the Kaplan-Meiermethod with a log-rank comparison for subgroups.

\section{Results}

\section{Patients}

In the 23 patients that were screened for differential expression of microRNAs, potentially prognostic and predictive characteristics were evenly distributed between relapse and control groups (Table 1, pilot phase). The median follow-up in the pilot cohort $(N=23)$ was 139 (range 26-190) and 133 months (range 98-187) for relapse and control patients, respectively (Table 2 ). In the validation cohort median follow-up was 125 (range 44-196) and 142 months (range 17-207) for relapse and control patients, respectively. In the relapse group of the pilot phase, two patients had distant metastases, occurring simultaneously with local recurrence in one case and eight months after local relapse in the other (Table 2). In the relapse group of the validation cohort, seven patients developed distant metastases, three of them at the time of local relapse, the other four at least 15 months after local relapse (Table 2). As for the target 
Fig. 1 a Screen for deregulated microRNAs: this heatmap shows the differentially expressed microRNAs with a raw $p$ value $<0.20$ (LIMMA, $N=23$ : 13 relapse patients and 10 controls). Hsa-miR-3651 has the highest statistical significance (relapse/ control fold change $=4.37$; raw $p$ value $=0.0035$ ). The fold changes (relapse/control) of a given miR are shown in green (high) and red (low). At the bottom the samples are shown: orange numbers refer to relapse patients, while controls are labeled blue. b Screen for de-regulated microRNAs: the median expression levels of hsa-miR-3651, image values from the microarray on the $y$-axis, were significantly higher in patients with local relapse compared to controls $(N=23$; Pearson correlation, $p$ value $=$ 0.004)
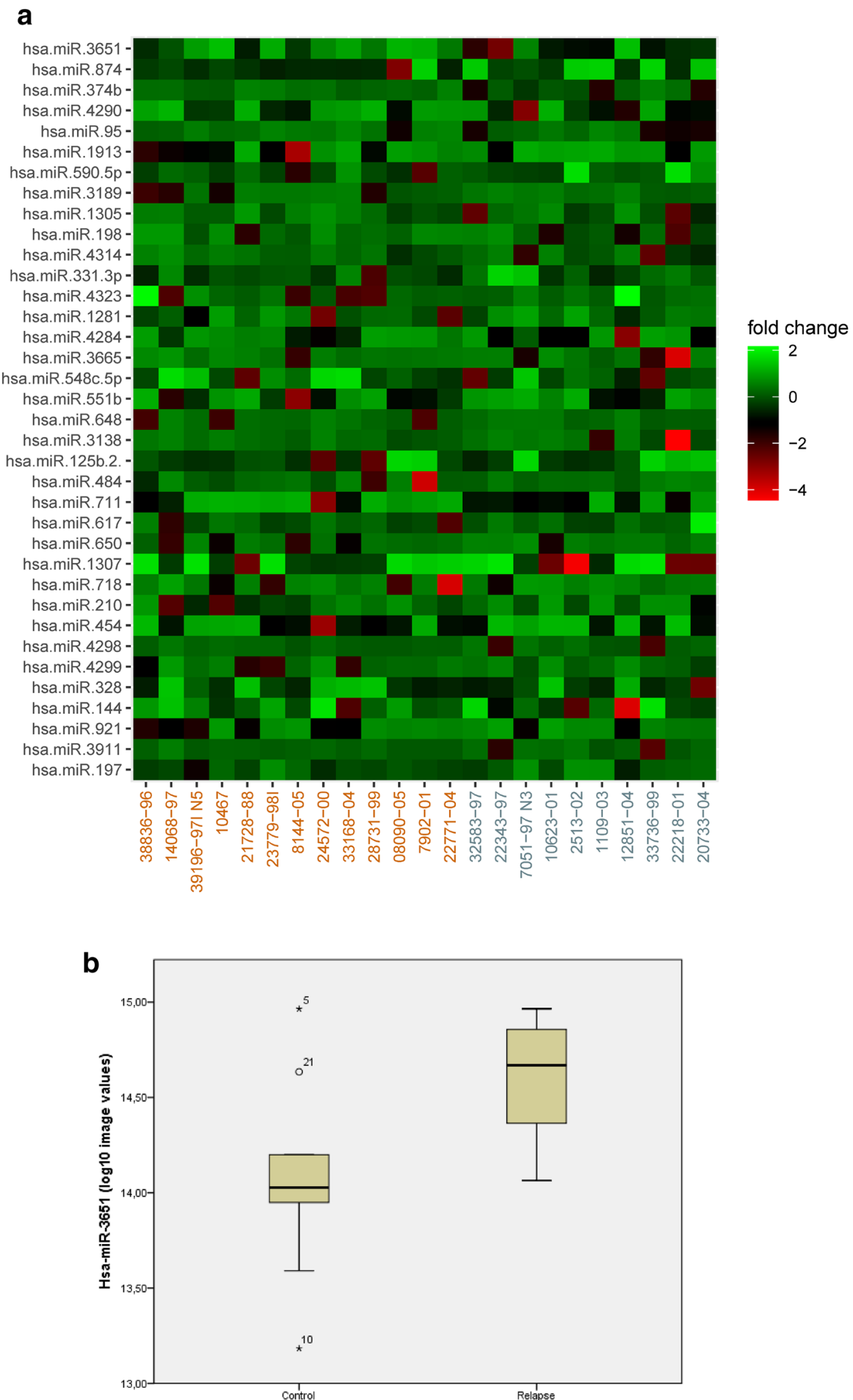

protein analysis, 41 patients were screened in the pilot phase $(N=21)$ and validated in an independent set of patients $(N=20)$. Again, potentially prognostic and predictive factors were evenly distributed between groups (Table 3 ). The median follow-up in the pilot phase was 139 (range 26-190) and 133 (98-187) months, respectively. In the validation phase the median follow-up amounted to 110 (range 44-192) and 124 (72-195) months, respectively. Three patients had 


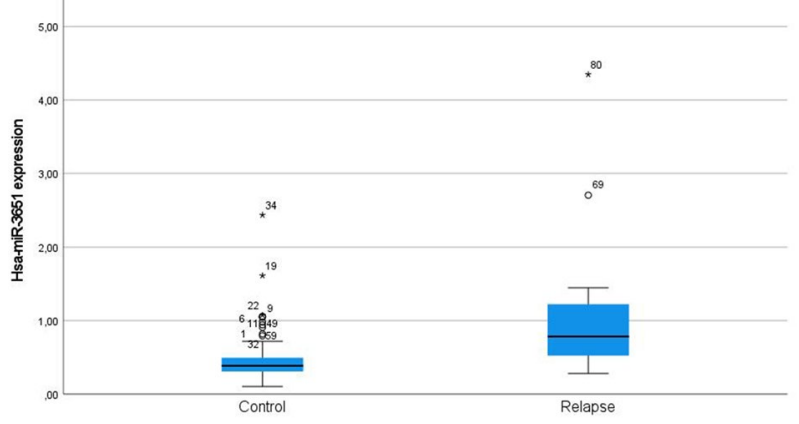

Fig. 2 Validation of the most de-regulated candidate microRNA, i.e., hsa-miR-3651, by means of RT-qPCR. Hsa-miR-3651 expression levels in patients with local relapse were significantly higher than in controls $(N=87$, Mann-Whitney test, $p$ value $<0.0005)$. The fold change (relapse/control) was 2.86

metastases at the time of local relapse (two in the pilot and one in the validation phase), while one patient in the validation phase experienced isolated local relapse 24 months before distant progression (Table 4).

\section{MiRNA—pilot phase}

The microarray revealed hsa-miR-3651 as the most differentially expressed miRNA $(N=23$, fold change 4.37 ; raw $p$ value $=0.0035$; Fig. 1a, b). The array data were deposited in NCBI Gene Expression Omnibus (GEO): http://www.ncbi. nlm.nih.gov/geo/query/acc.cgi?acc=GSE69951.

\section{MiRNA—validation phase}

The discriminatory potential with respect to LC was validated in an independent cohort. The levels of hsa-miR-3651 in these 87 patients were significantly elevated in the relapse group ( $p$ value $<0.0005$; fold change of 2.86 ; Fig. 2 ). In the time-to-event analysis high expression of hsa-miR-3651 correlated to a significantly enhanced risk of local relapse ( $p$ value $=0.021 ;$ Fig. $3 \mathrm{a}$ ). The corresponding ROC analysis revealed an AUC of 0.778 ( $p$ value $<0.0005$, Fig. $3 b$ ).

\section{Target proteins-pilot phase}

The patient and treatment characteristics of the 21 eligible revealed no significant differences between relapse and control groups (Table 3). The median follow-up was 139 (range: 26-190) and 133 months (range: 98-187) for relapse patients and controls, respectively (Table 4). Among the 168 potential target molecules, FRMD3 had a prediction score of $94.5 \%$ (miRCarta, accessed February 2021) with an $8 \mathrm{mer}$ binding site, which made it a plausible target candidate. This was corroborated by our screen (Fig. 4; supplementary file 2), which revealed FRMD3 as the most significantly
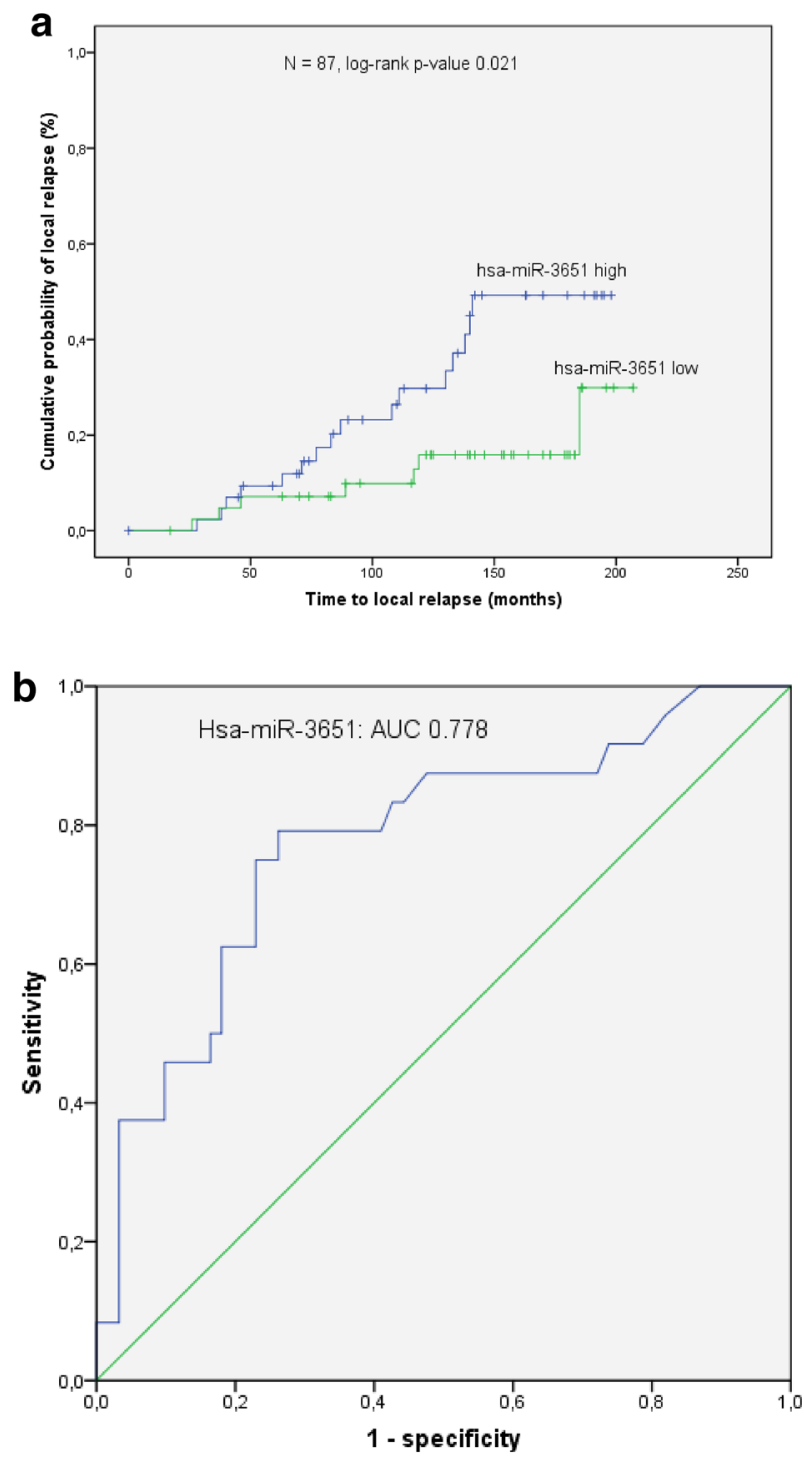

Fig. 3 a In the time to event analysis (event $=$ local relapse) patients with expression levels of hsa-miR-3651 above median (= hsa-miR-3651 high) had a significantly higher probability for local relapse than those with low levels of the microRNA $(N=87$, log-rank $p$ value $=0.021)$. b The ROC analysis of hsa-miR-3651 revealed an AUC $=0.778$ (Mann-Whitney test; $p$ value $<0.0005)$

down-regulated gene $(N=21$ patients, $p$ value $=0.0016)$. The array data were deposited in NCBI GEO (http://www. ncbi.nlm.nih.gov/geo/query/acc.cgi?acc=GSE156873). In this context, age deterioration plays an important role. Not surprisingly, this phenomenon could be observed in our analysis as well (supplementary file 2; Spearman correlation test, $p$ value $=0.021$ ). Nevertheless it did not impact the comparison between relapse patients and controls, since the age distribution between the two groups was similar (supplementary file 3; Mann-Whitney test, $p$ value $=0.264$ ). 




Fig. 4 This heatmap shows the mRNA expression (fold change relapse/control) of seven target proteins that were down-regulated in relapse patients. FRMD3 was the most prominent molecule with a raw $p$ value $=0.0016$ (Mann-Whitney test). The numbers at the bot- tom refer to relapse patients (orange) and controls (blue). The color bar at the right indicates the fold change: while green means relative over-expression, red signifies down-regulation
Fig. 5 a Validation of the most prominently de-regulated target protein by means of ddPCR: patients with FRMD3 expression above median had longer time to local relapse $(N=20$; one-sided Pearson correlation, $p$ value $=0.164)$. $\mathbf{b}$ The correlation of the combined marker hsa-miR-3651/FRMD3 to local relapse revealed that the relapse group had a higher expression level of hsa-miR-3651 compared to FRMD3 (one-sided Pearson test, $p$ value $=0.134$ )



b






\section{Target proteins-validation phase}

In an independent set of 20 individuals ( 9 relapses/11 controls), higher levels of FRMD3, i.e., above median, predicted longer latency to in-breast recurrence ( $p$ value $=0.164$, Fig. 5a). As for the combined marker hsa-miR-3651/ FRMD3, a higher level of the microRNA compared to the target protein was observed in the relapse group ( $p$ value $=0.134$, Fig. $5 \mathrm{~b}$ ). This result was corroborated as a tendency in a time-to-event analysis (log-rank $p$ value $=0.260$; supplementary file 5). Age dependent mRNA degradation was detectable in this part of the study, yet without influence on the results (supplementary file 7; Mann-Whitney test, $p$ value $=0.518$ ).

\section{Discussion}

The current analysis revealed hsa-miR-3651 as a novel predictor for LC in early breast cancer. Additionally, FRMD3 was identified as a putative target that interferes with protein binding as well as cytoskeletal and cell membrane stability.

While hsa-miR-3651 has been described as a discriminatory marker in other cancer types, such as head and neck [9, 10], ovaries [11], colorectal [12], liver [13], lung [14] and nephroblastoma [30], the current analysis is the first in breast cancer. From the viewpoint of sample selection, the study by Tuncer can be regarded as related to ours, in as far as it also investigates hormone dependent tissue. [11]. The authors analyzed microRNA profiles in peripheral blood lymphocytes of monozygotic twins with ovarian cancer and healthy relatives. They also found up-regulated hsamiR-3651 in cancer patients [11]. A study in oral squamous cell carcinoma (OSCC) comparing healthy versus tumor tissue showed elevated levels of hsa-miR-3651 in the latter $[9,10]$ with a fold change of 2.5 . Likewise, the authors of this study detected a correlation between hsa-miR-3651 and clinical features that indicate loco-regional invasiveness, such as lymph node stage. In contrast, Wang et al. showed that the down-regulation of hsa-miR-3651 in esophageal cancer patients led to worse OS and DFS [31]. The authors could also demonstrate a correlation between clinical factors that add to loco-regional aggressiveness, such as $\mathrm{T}$-, $\mathrm{N}$-stage and tumor length and the expression levels of hsa-miR-3651, implying that this micro-RNA may exert its (patho)physiological function in a tissue dependent manner [31].

As for the role of hsa-miR-3651 and its potential interference in functional pathways, FRMD3 was identified as a putative target by microarray technology (Fig. 4) and validated in an independent set of patient using ddPCR (Figs. 5; supplementary file 5). This molecule, which belongs to the protein 4.1 superfamily, is characterized by the highly conserved membrane-association domain FERM [15]. Although comprehensive analyses about its functioning are not available to date, it is generally assumed that it links cytoskeletal structures, i.e., actin filaments, to membrane proteins, which enhances cellular stability and impacts loco-regional invasiveness [16, 17, 32] (GeneCodis 4.0 accessed February 2021, supplementary file 6). Apart from its role in metabolic diseases [33-36], FRMD3 was reported to be focally expressed in hormone dependent tissue, i.e., adult ovary [37]. Additionally, in 58 NSCLC patient samples, Haase et al. found down-regulated FRMD3 in tumor compared to normal tissue [15]. In cell experiments the authors could show that it was able to induce apoptosis via the extrinsic, i.e., membrane dependent, pathway [15]. In contrast, reports on rectal $[38,39]$ and colon cancer [40] revealed that upregulation of FRMD3 was associated with worse response to chemoradiotherapy. In two of the mentioned studies this molecule formed part of a multi-gene signature [39, 40]. In the third analysis, it was found to be the most up-regulated gene in nonresponders among 172 patients receiving cCRT [38]. Unfortunately, the authors did not verify their results in an independent set of individuals.

In summary, it can be said that in our study the de-regulation of hsa-miR-3651 measured as fold change is in the same range as in the above mentioned papers [9-11]. With due caution it can be assumed that this microRNA plays a role in loco-regional invasiveness [31], which is, at least to some extent, corroborated by the current study. In this context, FRMD3, identified as a potential target, might play a crucial role $[16,17]$. Discrepancies with other studies can be explained by differences in the choice of clinical material and methodology. Our analysis was conducted in breast cancer, while published data originate from other tissues [9, $10,31]$. The current study compares primary tumor samples of patients with and without relapse, while other analyses used normal tissue specimens as controls. Since a major technical challenge consists in improving the "signal to noise ratio", only specimen with at least 50\% tumor content were selected, which is comparable to published literature [20]. Other groups chose a higher cancer cell cutoff [6] or used micro-dissection $[18,19]$ in order to maximize the tumor signal. Finally, the interplay between different types of miRNAs is an issue, therefore we focused on single microRNAs. Since clustered miRNAs, which make up approximately $25 \%$ of the whole miRnome, are located in close genomic vicinity their transcriptional efficacy is presumably higher than that of single microRNAs [21]. Hence, it does not seem counterintuitive to assume that the latter are underrepresented in whole miRNome investigations. To account for this potential loss of information, miRNA families were excluded in the current analysis.

In spite of a predicted $94.5 \%$ probability for the interaction between hsa-miR-3651 and FRMD3, no mechanistic evidence on a cellular level is extant thus far. Secondly, the 
direct measurement of FRMD3 protein levels, which would have certainly strengthened our results, was impossible both for lack of a suitable antibody and the small number of cases in the protein validation phase. Our results, however, are coherent with the two-fold physiological functioning of a microRNA, which results in decreased mRNA levels of a target protein either by RISC-mediated dissection of the mRNA molecule based on a perfect miRNA-mRNA binding or delayed degradation by less exact match. Hence, changes in mRNA levels can be regarded as an indirect measure for protein concentrations. Additionally, an 8mer miR-mRNA binding site allows to postulate a close affinity between hsamiR-3651 and FRMD3. A general disadvantage of molecular analyses in samples of a certain age is the degradation of the tissue, which could also be observed in the current study (supplementary files 2, 3, 7).

\section{Conclusions}

The current analysis demonstrates that hsa-miR-3651 may predict local control in early breast cancer via FRMD3. This hypothesis generating study provides a sound hypothesis to be tested in larger prospective studies, so that our results contribute to the framework of personalized medicine for this disease in the long run.

Supplementary Information The online version contains supplementary material available at https://doi.org/10.1007/s12282-021-01308-y.

Author contributions Conceptualization: $\mathrm{CK}$ and FZ; funding acquisition: FS and FZ; formal analysis and investigation: BZ, UB, IE, BG and JK; methodology, BZ, IE, CK, MS, GF and KS; supervision: KS, FS and FZ; writing - original draft: BG and FZ; writing - review and editing: BZ, UB, FS and FZ.

Funding Open access funding provided by Paracelsus Medical University. This study was Funded by the following grants: Paracelsus Medical University: PMU-FFF, Österreichische Krebshilfe Salzburg, grant 2017-2018.

Data availability The array data were deposited in NCBI Gene Expression Omnibus under the accession numbers GSE69951 and GSE 156873, respectively; they can be downloaded via the following links: http://www.ncbi.nlm.nih.gov/geo/query/acc.cgi?acc=GSE69951, http://www.ncbi.nlm.nih.gov/geo/query/acc.cgi?acc=GSE156873.

\section{Declarations}

Conflicts of interest Barbara Zellinger, Ulrich Bodenhofer, Immanuela Engländer, Cornelia Kronberger, Brane Grambozov, Elvis Ruznic, Markus Stana, Josef Karner, Gerd Fastner, Karl Sotlar, Felix Sedlmayer and Franz Zehentmayr declare that they have no conflict of interest.

Ethical approval All procedures performed in studies involving human participants were in accordance with the ethical standards of the Insti- tutional and National Research Committee and with the 1964 Helsinki Declaration and its later amendments or comparable ethical standards.

Informed consent Informed consent was obtained from all individuals included in the study.

Open Access This article is licensed under a Creative Commons Attribution 4.0 International License, which permits use, sharing, adaptation, distribution and reproduction in any medium or format, as long as you give appropriate credit to the original author(s) and the source, provide a link to the Creative Commons licence, and indicate if changes were made. The images or other third party material in this article are included in the article's Creative Commons licence, unless indicated otherwise in a credit line to the material. If material is not included in the article's Creative Commons licence and your intended use is not permitted by statutory regulation or exceeds the permitted use, you will need to obtain permission directly from the copyright holder. To view a copy of this licence, visit http://creativecommons.org/licenses/by/4.0/.

\section{References}

1. Carioli G, Malvezzi M, Rodriguez T, Bertuccio P, Negri E, La Vecchia C. Trends and predictions to 2020 in breast cancer mortality in Europe. Breast. 2017;36:89-95.

2. Darby S, McGale P, Correa C, Taylor C, Arriagada R, Clarke M, et al. Effect of radiotherapy after breast-conserving surgery on 10 -year recurrence and 15-year breast cancer death: meta-analysis of individual patient data for 10,801 women in 17 randomised trials. Lancet. 2011;378(9804):1707-16.

3. Bentzen SM, Agrawal RK, Aird EG, Barrett JM, Barrett-Lee PJ, Bliss JM, et al. The UK standardisation of breast radiotherapy (START) trial A of radiotherapy hypofractionation for treatment of early breast cancer: a randomised trial. Lancet Oncol. 2008;9(4):331-41.

4. Iorio MV, Ferracin M, Liu CG, Veronese A, Spizzo R, Sabbioni $\mathrm{S}$, et al. MicroRNA gene expression deregulation in human breast cancer. Cancer Res. 2005;65(16):7065-70.

5. Goldhirsch A, Wood WC, Coates AS, Gelber RD, Thurlimann B, Senn HJ. Strategies for subtypes-dealing with the diversity of breast cancer: highlights of the St. Gallen International Expert Consensus on the Primary Therapy of Early Breast Cancer 2011. Ann Oncol. 2011;22(8):1736-47.

6. Zhou X, Marian C, Makambi KH, Kosti O, Kallakury BV, Loffredo CA, et al. MicroRNA-9 as potential biomarker for breast cancer local recurrence and tumor estrogen receptor status. PLoS ONE. 2012;7(6):e39011.

7. Zehentmayr F, Hauser-Kronberger C, Zellinger B, Hlubek F, Schuster C, Bodenhofer U, et al. Hsa-miR-375 is a predictor of local control in early stage breast cancer. Clin Epigenet. 2016;8:28

8. Zellinger B, Bodenhofer U, Englander IA, Kronberger C, Strasser P, Grambozov B, et al. Hsa-miR-375/RASD1 signaling may predict local control in early breast cancer. Genes. 2020. https://doi. org/10.3390/genes11121404.

9. Ries J, Baran C, Wehrhan F, Weber M, Motel C, Kesting M, et al. The altered expression levels of miR-186, miR-494 and miR-3651 in OSCC tissue vary from those of the whole blood of OSCC patients. Cancer Biomark. 2019;24(1):19-30.

10. Ries J, Vairaktaris E, Agaimy A, Kintopp R, Baran C, Neukam FW, et al. miR-186, miR-3651 and miR-494: potential biomarkers for oral squamous cell carcinoma extracted from whole blood. Oncol Rep. 2014;31(3):1429-36. 
11. Tuncer SB, Erdogan OS, Erciyas SK, Saral MA, Celik B, Odemis DA, et al. miRNA expression profile changes in the peripheral blood of monozygotic discordant twins for epithelial ovarian carcinoma: potential new biomarkers for early diagnosis and prognosis of ovarian carcinoma. J Ovarian Res. 2020. https://doi.org/ 10.1186/s13048-020-00706-8.

12. Li CF, Ding DY, Gao YJ, Li YC. MicroRNA-3651 promotes colorectal cancer cell proliferation through directly repressing T-box transcription factor 1. Int J Mol Med. 2020;45(3):956-66.

13. Zhao XY, Song QL, Miao G, Zhu XF. MicroRNA-3651 promotes the growth and invasion of hepatocellular carcinoma cells by targeting PTEN. Oncotargets Ther. 2019;12:7045-54.

14. Guo HS, Chen JK, Meng FL. Identification of novel diagnosis biomarkers for lung adenocarcinoma from the cancer genome atlas. Int J Clin Exp Med. 2016;9(5):7908-18.

15. Haase D, Meister M, Muley T, Hess J, Teurich S, Schnabel P, et al. FRMD3, a novel putative tumour suppressor in NSCLC. Oncogene. 2007;26(30):4464-8.

16. Patel H, Konig I, Tsujioka M, Frame MC, Anderson KI, Brunton VG. The multi-FERM-domain-containing protein FrmA is required for turnover of paxillin-adhesion sites during cell migration of Dictyostelium. J Cell Sci. 2008;121(8):1159-64.

17. Lo SH. Focal adhesions: what's new inside. Dev Biol. 2006;294(2):280-91.

18. Skalicky S, Zwiers PJ, Kuiper T, Schraml E, Hackl M, Molema G. Combining laser microdissection and microRNA expression profiling to unmask microRNA signatures in complex tissues. Biotechniques. 2019;67(6):276-85.

19. Perez-Rivas LG, Jerez JM, Carmona R, de Luque V, Vicioso L, Claros MG, et al. A microRNA signature associated with early recurrence in breast cancer. PLoS ONE. 2014;9(3):e91884.

20. Lyng MB, Laenkholm AV, Sokilde R, Gravgaard KH, Litman T, Ditzel HJ. Global microRNA expression profiling of high-risk $\mathrm{ER}+$ breast cancers from patients receiving adjuvant tamoxifen mono-therapy: a DBCG study. PLoS ONE. 2012;7(5):e36170.

21. Kabekkodu SP, Shukla V, Varghese VK, D'Souza J, Chakrabarty $\mathrm{S}$, Satyamoorthy K. Clustered miRNAs and their role in biological functions and diseases. Biol Rev. 2018;93(4):1955-86.

22. Huang E, Buchholz TA, Meric F, Krishnamurthy S, Mirza NQ, Ames FC, et al. Classifying local disease recurrences after breast conservation therapy based on location and histology: new primary tumors have more favorable outcomes than true local disease recurrences. Cancer. 2002;95(10):2059-67.

23. Livak KJ, Schmittgen TD. Analysis of relative gene expression data using real-time quantitative PCR and the $2^{-\Delta \Delta C T}$ method. Methods. 2001;25(4):402-8.

24. McCall MN, Murakami PN, Lukk M, Huber W, Irizarry RA. Assessing affymetrix GeneChip microarray quality. BMC Bioinform. 2011. https://doi.org/10.1186/1471-2105-12-137.

25. Irizarry RA, Bolstad BM, Collin F, Cope LM, Hobbs B, Speed TP. Summaries of affymetrix GeneChip probe level data. Nucleic Acids Res. 2003. https://doi.org/10.1093/nar/gng015.

26. Carvalho BS, Irizarry RA. A framework for oligonucleotide microarray preprocessing. Bioinformatics. 2010;26(19):2363-7.

27. Smyth GK. Linear models and empirical bayes methods for assessing differential expression in microarray experiments. Stat Appl Genet Mol Biol. 2004. https://doi.org/10.2202/1544-6115. 1027.

28. Benjamini Y, Hochberg Y. Controlling the false discovery rate-a practical and powerful approach to multiple testing. J Roy Stat Soc B Met. 1995;57(1):289-300.
29. Dhawan A, Scott JG, Harris AL, Buffa FM. Pan-cancer characterisation of microRNA across cancer hallmarks reveals microRNAmediated downregulation of tumour suppressors. Nat Commun. 2018. https://doi.org/10.1038/s41467-018-07657-1.

30. Ludwig N, Nourkami-Tutdibi N, Backes C, Graf N, Keller A, Meese E. Longitudinal study identifies 3 Mirna signatures allowing differentiation between patients with Wilms tumors and controls at diagnosis, after surgery and at time of relapse. Pediatr Blood Cancer. 2015;62:S175-S175.

31. Wang C, Guan S, Chen X, Liu B, Liu F, Han L, et al. Clinical potential of miR-3651 as a novel prognostic biomarker for esophageal squamous cell cancer. Biochem Biophys Res Commun. 2015. https://doi.org/10.1016/j.bbrc.2015.07.109.

32. Buffon MP, Sortica DA, Gerchman F, Crispim D, Canani LH. FRMD3 gene: its role in diabetic kidney disease. A narrative review. Diabetol Metab Syndr. 2015. https://doi.org/10.1186/ s13098-015-0114-4.

33. Pezzolesi MG, Poznik GD, Mychaleckyj JC, Paterson AD, Barati MT, Klein JB, et al. Genome-wide association scan for diabetic nephropathy susceptibility genes in type 1 diabetes. Diabetes. 2009;58(6):1403-10.

34. Maeda S, Araki S, Babazono T, Toyoda M, Umezono T, Kawai K, et al. Replication study for the association between four loci identified by a genome-wide association study on European American Subjects With Type 1 Diabetes and Susceptibility to Diabetic Nephropathy in Japanese Subjects with type 2 diabetes. Diabetes. 2010;59(8):2075-9.

35. Palmer ND, Ng MCY, Hicks PJ, Mudgal P, Langefeld CD, Freedman BI, et al. Evaluation of candidate nephropathy susceptibility genes in a genome-wide association study of African American Diabetic Kidney Disease. PLoS ONE. 2014. https://doi.org/10. 1371/journal.pone.0088273.

36. Liang JJ, Le TH, Edwards DRV, Tayo BO, Gaulton KJ, Smith JA, et al. Single-trait and multi-trait genome-wide association analyses identify novel loci for blood pressure in African-ancestry populations. PLoS Genet. 2017. https://doi.org/10.1371/journal. pgen.1006728.

37. Ni XH, Ji CN, Cao GT, Cheng HP, Guo LC, Gu SH, et al. Molecular cloning and characterization of the protein 4.10 gene, a novel member of the protein 4.1 family with focal expression in ovary. J Hum Genet. 2003;48(2):101-6.

38. Chen TJ, Chou CL, Tian YF, Yeh CF, Chan TC, He HL, et al. High FRMD3 expression is prognostic for worse survival in rectal cancer patients treated with CCRT. Int J Clin Oncol. 2021;26(9):1689-97.

39. Watanabe T, Kobunai T, Akiyoshi T, Matsuda K, Ishihara S, Nozawa K. Prediction of response to preoperative chemoradiotherapy in rectal cancer by using reverse transcriptase polymerase chain reaction analysis of four genes. Dis Colon Rectum. 2014;57(1):23-31.

40. Zhang CG, Zhao Z, Liu HB, Yao SK, Zhao DY. Weighted gene co-expression network analysis identified a novel thirteen-gene signature associated with progression, prognosis, and immune microenvironment of colon adenocarcinoma patients. Front Genet. 2021. https://doi.org/10.3389/fgene.2021.657658.

Publisher's Note Springer Nature remains neutral with regard to jurisdictional claims in published maps and institutional affiliations. 